\title{
Trends and acceleration in global and regional sea levels since 1807
}

\author{
S. Jevrejeva ${ }^{\text {a,b }}$, J.C. Moore ${ }^{\text {a,c,d, }, *}$, A. Grinsted ${ }^{\text {a,e }}$, A.P. Matthews ${ }^{\text {b }}$, G. Spada ${ }^{\text {f }}$ \\ a State Key Laboratory of Earth Surface Processes and Resource Ecology, College of Global Change and Earth System Science, Beijing Normal University, Beijing, China \\ ${ }^{\mathrm{b}}$ National Oceanography Centre, Liverpool, UK

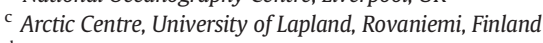 \\ ${ }^{d}$ Department of Earth Sciences, Uppsala University, Uppsala, Sweden \\ e Centre for Ice and Climate, Niels Bohr Institute, University of Copenhagen, Denmark \\ f Dipartimento di Scienze di Base e Fondamenti, Università degli Studi “Carlo Bo”, I-61029 Urbino, Italy
}

\section{A R T I C L E I N F O}

\section{Article history:}

Received 2 August 2013

Received in revised form 2 December 2013

Accepted 2 December 2013

Available online 11 December 2013

\section{Keywords:}

sea level trends

sea level acceleration

tide gauge records

GIA corrections

\begin{abstract}
A B S T R A C T
We use 1277 tide gauge records since 1807 to provide an improved global sea level reconstruction and analyse the evolution of sea level trend and acceleration. In particular we use new data from the polar regions and remote islands to improve data coverage and extend the reconstruction to 2009. There is a good agreement between the rate of sea level rise $\left(3.2 \pm 0.4 \mathrm{~mm} \cdot \mathrm{yr}^{-1}\right)$ calculated from satellite altimetry and the rate of $3.1 \pm 0.6 \mathrm{~mm} \cdot \mathrm{yr}^{-1}$ from tide gauge based reconstruction for the overlapping time period (1993-2009). The new reconstruction suggests a linear trend of $1.9 \pm 0.3 \mathrm{~mm} \cdot \mathrm{yr}^{-1}$ during the 20 th century, with $1.8 \pm 0.5 \mathrm{~mm} \cdot \mathrm{yr}^{-1}$ since 1970 . Regional linear trends for 14 ocean basins since 1970 show the fastest sea level rise for the Antarctica $\left(4.1 \pm 0.8 \mathrm{~mm} \cdot \mathrm{yr}^{-1}\right)$ and Arctic $\left(3.6 \pm 0.3 \mathrm{~mm} \cdot \mathrm{yr}^{-1}\right)$. Choice of GIA correction is critical in the trends for the local and regional sea levels, introducing up to $8 \mathrm{~mm} \cdot \mathrm{yr}^{-1}$ uncertainties for individual tide gauge records, up to $2 \mathrm{~mm} \cdot \mathrm{yr}^{-1}$ for regional curves and up to $0.3-0.6 \mathrm{~mm} \cdot \mathrm{yr}^{-1}$ in global sea level reconstruction. We calculate an acceleration of $0.02 \pm 0.01 \mathrm{~mm} \cdot \mathrm{yr}^{-2}$ in global sea level (1807-2009). In comparison the steric component of sea level shows an acceleration of $0.006 \mathrm{~mm} \cdot \mathrm{yr}^{-2}$ and mass loss of glaciers accelerates at $0.003 \mathrm{~mm} \cdot \mathrm{yr}^{-2}$ over 200 year long time series.
\end{abstract}

(C) 2013 Elsevier B.V. All rights reserved.

\section{Introduction}

Our understanding of the present day sea level rise has changed considerably over the past 10-20 years. Satellite altimetry measurements since 1993 have provided unique information about changes in global and regional mean sea levels, suggesting the rate of $3.2 \mathrm{~mm} \cdot \mathrm{yr}^{-1}$ global sea level rise for the period 1993-2012 (Boening et al., 2012; Cazenave et al., 2012), which notably exceeds the estimate of $1.8 \mathrm{~mm} \cdot \mathrm{yr}^{-1}$ sea level rise for the 20th century (Bindoff et al., 2007). However, there have been suggestions that the rate is not historically exceptional. For example, similar rates were observed in tide gauge records during the period 1920-1950 (Jevrejeva et al., 2006) and in decadal mean rates in the 1950s and 1970s (Church and White, 2006), and even a rate of $5.3 \mathrm{~mm} \cdot \mathrm{yr}^{-1}$ centred on the 1980 s by Holgate (2007).

To identify the long-term changes and variability of sea level over the past 200 years the tide gauge records provide the only instrumental

\footnotetext{
* Corresponding author at: State Key Laboratory of Earth Surface Processes and Resource Ecology, College of Global Change and Earth System Science, Beijing Normal University, Beijing, China. Tel.: + 8613521460942 ; fax: +86 1058802165.

E-mail address: john.moore.bnu@gmail.com (J.C. Moore).
}

data available. Individual tide gauge observations (Douglas, 1997), global sea level (GSL) reconstructions using tide gauge data (Gornitz et al., 1982; Jevrejeva et al., 2006; Grinsted et al., 2007; Jevrejeva et al., 2008a,b; Merrifield et al., 2009; Ray and Douglas, 2011), and reconstructions that jointly use satellite altimetry and tide gauge records (Church and White, 2006, 2011) show evolution of sea level rise for the past $50-100$ years.

In this study we renew the global sea level reconstruction by Jevrejeva et al. (2006), using monthly mean sea level data collected by Permanent Service for Mean Sea Level (PSMSL) covering the observations from 1807 to 2010 . Here we improve the GSL in three main respects: by increasing data coverage by using many more stations particularly in the polar regions, and recently processed historic data series from isolated island stations; we split the West Pacific region into north-western and south-western basins; and also extend the time covered by the reconstruction from 2002 to 2009. We analyse the difference between the rate of global sea level rise calculated using tide gauge and satellite altimetry measurements for the overlapping period 1993-2009. We perform several experiments with intent to gauge the uncertainties in GSL reconstructions associated with vertical land movement due to glacial isostatic adjustment (GIA) of the solid 


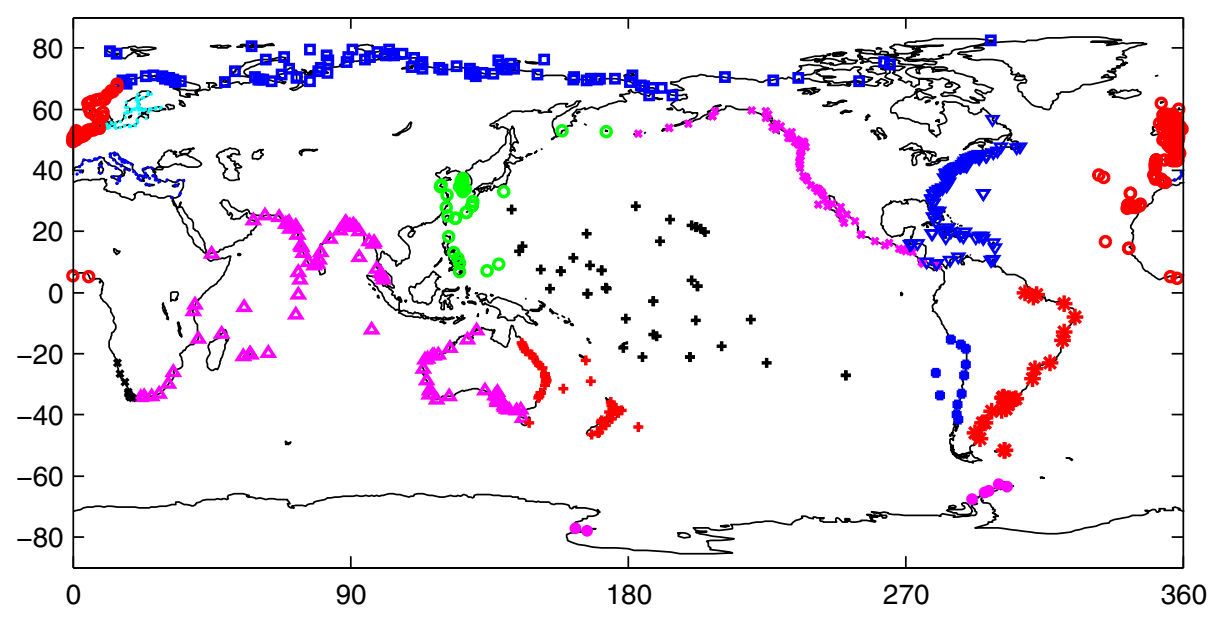

$\begin{array}{ll}\text { - } & \text { antarctic } \\ \text { - } & \text { arctic } \\ \text { + } & \text { baltic } \\ \Delta & \text { cpacific } \\ \text { - } & \text { indian } \\ \text { - } & \text { nediterr } \\ * & \text { neatlantic } \\ \nabla & \text { nwatlantic } \\ \text { - } & \text { nwpacific } \\ \text { * } & \text { seatlantic } \\ \text { - } & \text { sepacific } \\ * & \text { swatlantic } \\ \text { * } & \text { swpacific }\end{array}$

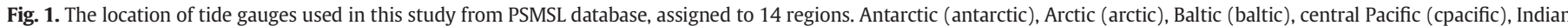

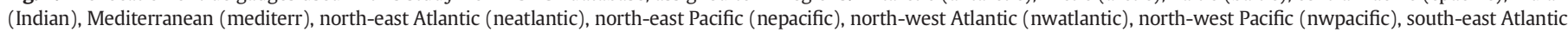
(seatlantic), south-east Pacific (sepacific), south-west Atlantic(swatlantic), south-west Pacific(swpacific).

Earth, using GIA corrections from different sources. Finally, we use our new reconstruction to estimate trends and acceleration in regional and global sea levels.

\section{Data and method}

\subsection{Data}

As with our previous reconstruction (Jevrejeva et al., 2006), data are available from http://www.psmsl.org/products/reconstructions/ jevrejevaetal2006.php. We have used Revised Local Reference (RLR) monthly mean time series from the Permanent Service for Mean Sea Level (PSMSL) database (Holgate et al., 2013). In this study we utilised an updated dataset of 1277 monthly mean time series covering the period 1807-2010 (Fig. 1). No inverted barometer correction was applied. In our study we have considered vertical land movement in tide gauge locations only from glacial isostatic adjustment (GIA) of the solid Earth (post glacial rebound). Sea level time series were corrected using the GIA corrections from the ICE 5G (ICE-5G v1.2) model (Peltier, 2004; data are available from http://www.psmsl.org/train_and_info/ geo_signals/gia/peltier/index.php). We have applied GIA corrections because the effect of glacial isostatic adjustment is a main source of contamination in tide gauge records globally. Modelled GIA corrections are available for each tide gauge location and have been used in all sea level reconstructions (e.g. Jevrejeva et al., 2006; Church and White, 2011; Ray and Douglas, 2011). There are other geophysical and anthropogenic signals over a range of spatial scales present in tide gauge data: vertical land movement due to earthquakes, groundwater extraction and sedimentation. In our study we have excluded data from Japan, due to lack of information about vertical land movement following the earthquakes. Ground water extraction or sedimentation in river deltas also affects some rapidly urbanizing localities, and we exclude tide gauge records from Bangkok and Manila in our reconstruction due to the uncertainties in corrections required to compensate for these õeffects. Estimates of vertical land movement from Global Positioning System (GPS) have been used for individual tide gauge locations (e.g. Woppelmann et al., 2009; Becker et al., 2012; King et al., 2012), however, the number of available GPS sites is limited to 100-300 (see Fig. 1, in King et al., 2012), and most of GPS sites are in Europe, North America and Japan. Polar regions, long coastal lines in South America, Africa, South-East Asia, coastal areas of Indian Ocean, and large part of Australian coast are not covered by the GPS observations. For the purpose of our study GPS derived vertical land movement corrections are available only for $10 \%$ of our 1277 tide gauge records and therefore have not been used for corrections.

We divided the global tide gauge network into 14 regions, where each "region" is representing a coast line of ocean basins with northsouth and west-east partitions (Fig. 1). We use tide gauge data located along the coast and therefore our global sea level reconstruction reflects changes in coastal areas only, but sea level trends from these sites are representative of the ocean basins they surround (see Section 3 and Prandi et al., 2009). The areas of each of our ocean basins are about $30,000,000 \mathrm{~km}^{2}$ except for the larger Indian ocean basin covering $73,000,000 \mathrm{~km}^{2}$. This basin may arguably be divided both east-west and north-south which would then result in regions that are too small, so we elect to keep it as a single basin. As the basins are of similar size and fairly evenly distributed over the globe, the global sea level reconstruction whether calculated using simple averages or calculated using an area weighted average performs equally well in all our tests.

We do not include the Baltic Sea region in our GSL reconstruction as it is quite isolated and is not very representative for global sea level variability as discussed by Jevrejeva et al. (2006). Nevertheless, we have created the regional curve for Baltic Sea and analysed its regional trend and variability. Data coverage for each region is shown in Fig. 2.

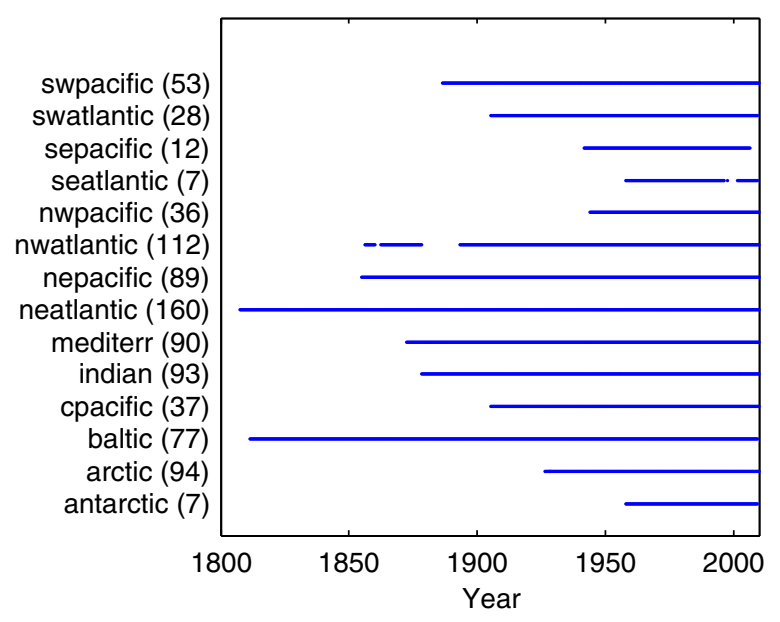

Fig. 2. Data coverage by regions with number of locations available for each region as defined in Fig. 1. 
The number of stations with available data for recent decades is limited by the lag between data collection and reporting (Holgate et al., 2013). The few stations available at the beginning of observational period are reflected in the dramatic increase in uncertainties. Data gaps shorter than one year in the final rate series are filled by interpolation.

\subsection{Method}

It is not easy to combine individual tide gauge records into a regional or global curve. Tide gauge measurements suffer from three main limitations:

- the geographical distribution of tide gauges is naturally confined to the continental margins and some ocean islands, which provides poor sampling of the ocean basins, in addition, most tide gauges are located in the Northern Hemisphere;

- available tide gauge records do not all cover the same time period;

- tide gauges are attached to the land, providing measurements relative to the Earth's crust. There is no common reference level for the individual tide gauge records and this creates a problem of stacking records together.

To overcome the geographical bias we applied the "virtual station method" (Jevrejeva et al., 2006; Grinsted et al., 2007). We first assign each station to the one of 14 regions (Figs. 1,2). We then recursively combine the two closest stations within a region (by averaging their records) into a new virtual station half-way between them until only one station remains in the region. This last remaining virtual station represents the mean sea level for the entire region. Our "virtual station" approach guarantees that tide gauge records are given more weight in regions where data coverage is sparse. In addition, for our "virtual station method" we have developed the techniques to quantify the uncertainties due to representativity issues of the utilised stations. Whenever a virtual station is created the uncertainty due representativity is calculated by looking at the deviation from the mean of the source stations over the period of common overlap. This uncertainty is combined with the underlying uncertainty of the two source records.

To combine individual tide gauge records in the region with no common reference level we calculate monthly rate of changes in sea level for each individual tide gauge and stack the rates (Jevrejeva et al., 2006). As we have described in Jevrejeva et al. (2006), historically many tide gauge records have been measured for some short time period (several months) of the year and annual cyclicity in sea level could lead to some bias. We calculate the mean annual rate for a given month over a whole year (e.g. the rate in January calculated as the July to July difference).

As we explained in Jevrejeva et al. (2006) the error for the virtual station in each region for the $i$ th year has been calculated as:

$e_{i}=\sqrt{m_{i}^{2}+r_{i}^{2}}$

where $m$ is the measurement error associated with each station measurement and $r$ is the misfit error, that is the difference in sea level trend recorded at the two stations in any particular year. The error $e$ is considered as a measurement error when a virtual station is merged with another station in the next step in the recursion. Normally time series from $x$ and $y$ do not span exactly the same period. The mean measurement error $(m)$ is then calculated as

$m_{i}=\frac{\sqrt{m_{x, i}^{2}+m_{y, i}^{2}}}{n_{i}}$,

where $m_{x}$ and $m_{y}$ are the measurement errors of station $x$ and $y$ respectively. In years where only one station has data $n_{i}=1$ and the other is simply left out of the equation, otherwise $n_{i}=2$. By calculating the misfit error we estimate how well the virtual station represents stations $x$ and $y$ and is written

$r_{i}=\frac{\sigma_{x y}}{2 \sqrt{n_{i}}}$

where $\sigma_{x y}$ is calculated as the standard deviation of the rates at $x$ minus those at $y$ over the interval of common overlap. At the end of recursive procedure we calculate the monthly sea level rate of the entire region and its associated error.

The GSL presented in Fig. 3 has been calculated by integrating the rate of change in GSL (dGSL), with the dGSL curve as the arithmetic average of the sea level rates for the following costal lines: north-east Pacific, south-east Pacific, north-west Pacific, south-west Pacific, central Pacific, Indian, Arctic, Antarctic, Mediterranean, north-east Atlantic, north-west Atlantic, south-east Atlantic and south-west Atlantic. The resulting GSL curve did not change appreciably by using area weighted average using the estimated area corresponding to each region.

The GSL is not exactly "the true" global sea level, there are uncertainties (1) due to variation in tide gauge geographical coverage and their locations only along the costal lines, which lead to representivity errors since regional differences in sea level trends are large (Jevrejeva et al., 2006, 2008b). This is predominant when individual coast lines are poorly sampled by tide gauge observations (Jevrejeva et al., 2006). The errors in tide gauge records are very highly auto-correlated (2) due to inertia in sea level components, such as the changes ocean heat content and cryosphere, which has been discussed in Grinsted et al. (2010). Additionally, as we integrate global sea level rates to calculate global sea level reconstruction, we also integrate errors (3), and therefore uncertainties increase with time both before and after the reference period (1980-1999).

To accommodate these three effects we estimate the uncertainty covariance matrix (C), quantifying the accumulating serially correlated uncertainty arising from the representativity of the regional records (Grinsted et al., 2010). In this study the $C$ matrix was calculated using a parametric Monte Carlo estimate, simulating the time-varying noise spectra of annual sea level rates in 14 regions. We find that the typical noise spectrum can be approximated as a sum of red and white noise processes. In our study we interpreted the red noise as the difference between regional sea level and "true" GSL, due, for example, to large scale processes such as circulation changes. The white noise represents the errors in the estimate of regional sea levels. The red noise component is unchanging in time, while the white noise component changes due to varying station coverage within a region. By minimizing the

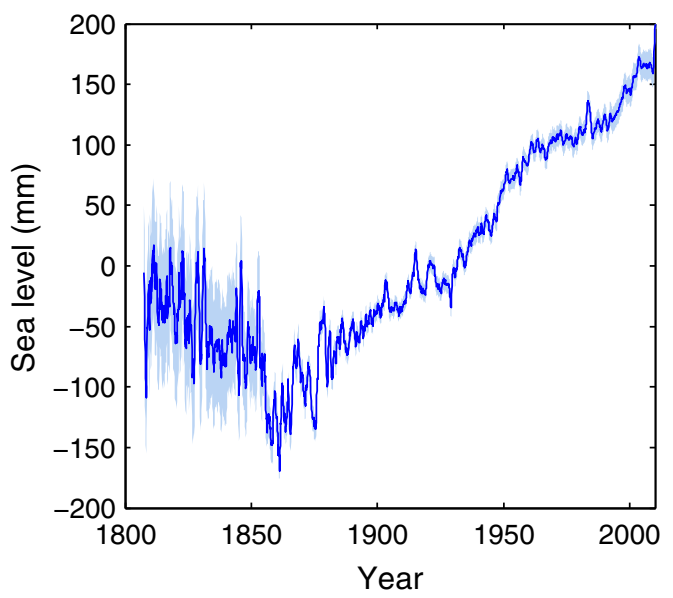

Fig. 3. Global sea level reconstruction since 1807, blue shadow represents 5 and $95 \%$ confidence interval. 


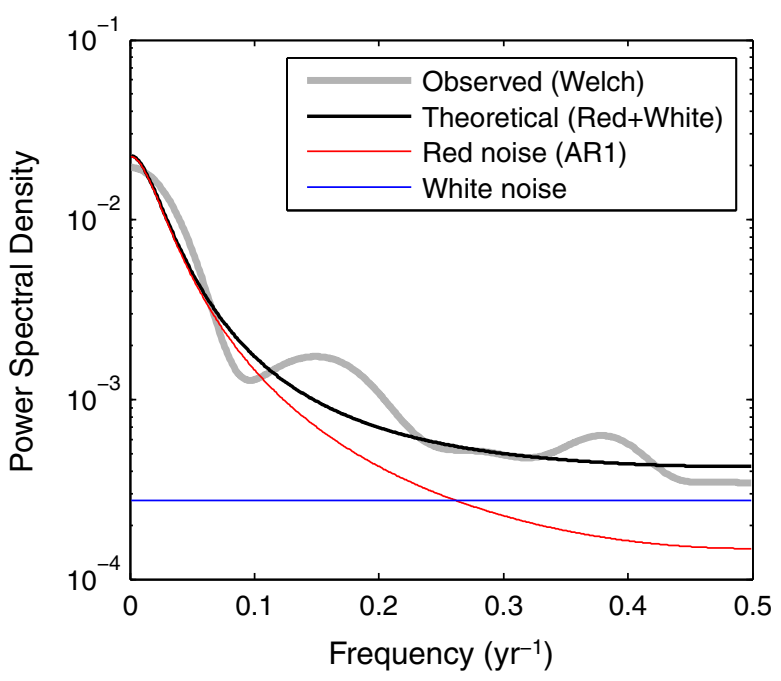

Fig. 4. Noise spectra estimated using the Welch method (Welch, 1967) of global sea level residuals (thick grey line) and the theoretical spectrum (thick black) from the sum of a red noise (red) and white noise (blue) process.

squared residuals between the observed spectrum and the theoretical spectrum (Fig. 4) the noise parameters for each region are estimated. Using these noise parameters we generate noise surrogates of regional sea level rate and GSL. The averaged noise auto-covariance matrix of 5000 Monte Carlo simulations is the uncertainty covariance matrix C. Fig. 5 shows the $C$ matrix for the reconstruction since 1807, with the lowest uncertainties during the period 1980-1999-the reference period. Uncertainty prior to 1850 s reflects the lack of tide gauge information from outside of Europe. The dominant characteristic in $C$ matrix is the persistent correlation in uncertainty reflected in the rectilinear error map due to the accumulation of errors. Moore et al. (2013) note that a leading diagonal in C matrix and the errors estimated using the approach described in Jevrejeva et al. (2006) and also used here to calculate monthly GSL errors (Eqs. (1)-(3)) shows that errors from the $\mathrm{C}$ matrix are larger by $5-15 \mathrm{~mm} \cdot \mathrm{yr}^{-1}$.

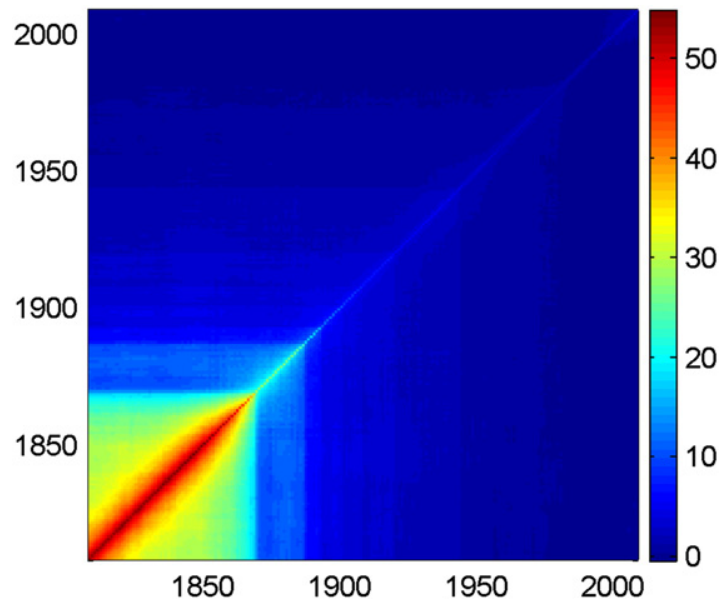

Fig. 5. Uncertainty covariance matrix C, for the global sea level reconstruction since 1807, colour bar in $\left(\mathrm{cm}^{2}\right)$. The lowest uncertainties are during the reference period (1980-1999). Uncertainty in early periods reflects tide gauge stations observations being only from Europe.

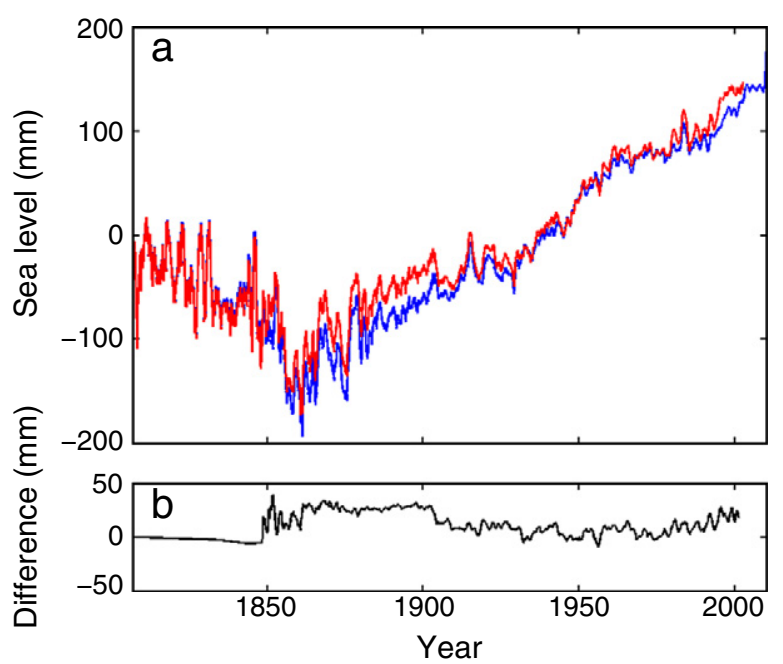

Fig. 6. Panel (a): GSL06 (red) and present study GSL12 (blue); panel (b) is the difference between two reconstruction (GSL06-GSL12).

\section{Results}

\subsection{Global monthly mean sea level reconstruction 1807-2010}

Global sea level reconstruction (GSL12) from 1277 tide gauge records located along the 14 coast lines is presented in Fig. 6. We compare GSL12 with sea level reconstruction from Jevrejeva et al. (2006), named GSL06. We have used the same method for both reconstructions, however, the main differences are in datasets: for the GSL06 we used 1023 tide gauges and 1277 for GSL12; the number of regions has increased from 13 to 14 (though we exclude the Baltic Sea in both reconstructed global sea level curves); and we used GIA corrections from ICE 4G in GSL06 and from ICE 5G for GLS12.

There is a noticeable difference between reconstructions for the early period of observations around 1850 (Fig. 6, panel b) due to additional historical time series becoming available for use in the present study. Since 1920 there are some differences in the monthly sea level rates of up to $\pm 3 \mathrm{~mm} \cdot \mathrm{yr}^{-1}$, however, the mean of the difference in rates is only $-0.01 \mathrm{~mm} \cdot \mathrm{yr}^{-1}$. Despite obvious dissimilarity in curves (Fig. 6) the linear trends for the 20th century are indistinguishable and result in $1.9 \pm 0.3 \mathrm{~mm} \cdot \mathrm{yr}^{-1}$. Experiments with repeated reconstructions using the GIA corrections from Peltier $(2001,2004)$ suggest that the choice of the GIA dataset is decisive and the difference in sea level reconstructions could reach up to $4 \mathrm{~cm}$ of total sea level rise during the 20th century, which is almost $20 \%$ of total sea level rise between 1900 and 1999.

For the period 1993-2009 we compare sea level calculated from satellite altimetry measurements (http://sealevel.colorado.edu/results. php) and our tide gauge based GSL12 (Fig. 7). We recalculated 10 day satellite altimetry sea level to the monthly mean values and compare with tide gauge based GSL12. Despite obvious differences in highfrequency variability in two time series the linear trends for the both datasets are not significantly different, with $3.1 \pm 0.6 \mathrm{~mm} \cdot \mathrm{yr}^{-1}$ from the tide gauge reconstruction and $3.2 \pm 0.4 \mathrm{~mm} \cdot \mathrm{yr}^{-1}$ from satellite altimetry (Fig. 7). This is consistent with the trend of $3.3 \pm 0.5 \mathrm{~mm} \cdot \mathrm{yr}^{-1}$, calculated from 91 selected tide gauge records, and altimetry-derived rate of $3.4 \pm 0.1 \mathrm{~mm} \cdot \mathrm{yr}^{-1}$ over the 15-year time span (1993-2007) published by Prandi et al. (2009). Differences in interannual variability of sea levels from tide gauge records and satellite altimetry has been discussed by Prandi et al. (2009), with many tide gauge records affected by coastal processes and regional variability, while the global mean sea level from satellite altimetry is calculated from open ocean areas. The consistency in trends of sea level between tide gauges and satellite 


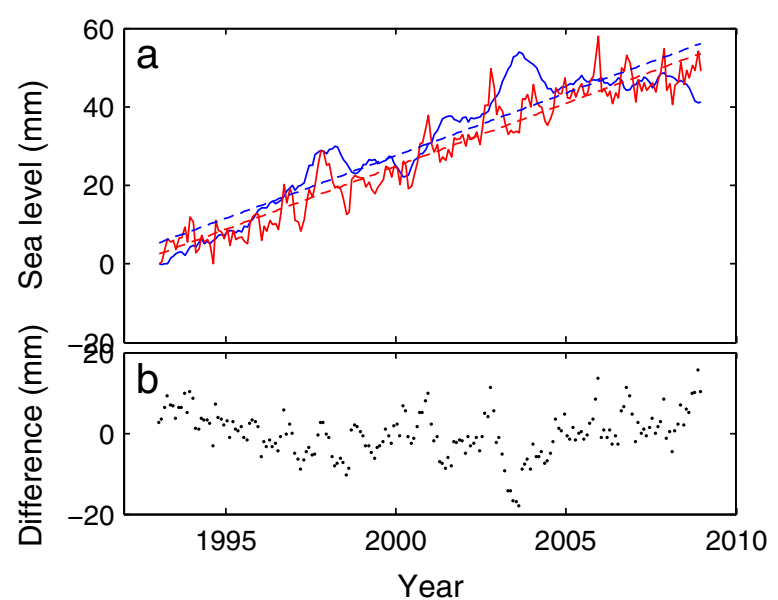

Fig. 7. Panel (a), global sea level from satellite altimetry recalculated to monthly mean values (red) and tide gauge based global sea level reconstruction (blue), 1993-2009. Dashed red and blue lines represent linear trends for satellite altimetry $\left(3.2 \mathrm{~mm} \cdot \mathrm{yr}^{-1}\right)$ and tide gauge $\left(3.1 \mathrm{~mm} \cdot \mathrm{yr}^{-1}\right)$ based sea levels. The difference between sea levels from satellite altimetry and tide gauge are black dots on panel (b).

altimetry over the period since 1993 suggests that historical information, which is only available from tide gauge data, provides a reasonably reliable method of estimating past low frequency (decadal and longer) variability and long term trends in global sea level.

We compare GSL12 with the Church and White (2011) (named here as CW11) reconstruction (http://www.cmar.csiro.au/sealevel/sl_data_ cmar.html). For the 20th century the linear trend in GSL12 is $1.9 \pm 0.3 \mathrm{~mm} \cdot \mathrm{yr}^{-1}$, compared with $1.7 \pm 0.2 \mathrm{~mm} \cdot \mathrm{yr}^{-1}$ from CW11 (Fig. 8). There is a notable difference between the reconstructions (Fig. 8b), particularly during the 1920-60s. One possible explanation may be due to the two distinctive methods used for reconstructions. Secondly, the tide gauge records used in the studies are very different;

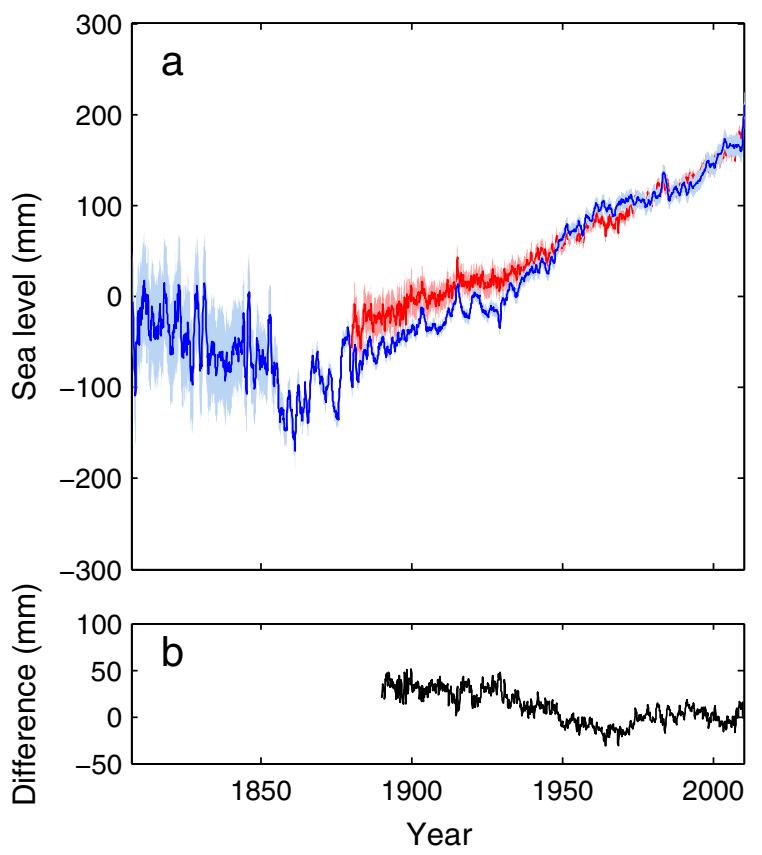

Fig. 8. Global sea level reconstruction by Church and White (2011) (CW11, red line) and the one presented here (GSL12, blue line), panel (a). Red shadow represents errors in CW11 and blue shadow represents errors in GSL12. Panel (b) shows the difference between the reconstructions. with 290 tide gauge records in CW11 and 1277 tide gauge datasets in this study. In addition, the Arctic and Antarctic regions were not included in the CW11 reconstruction. Omission of Arctic/Antarctica regional data from our global reconstruction reduces the difference between CW11 and GSL12, but does not eradicate it completely. Finally, some difference may be explained by the different GIA corrections used: CW11 used a combination of GIA corrections from Davis and Mitrovica (1996), Milne et al. (2001) and the ICE 4G model (Peltier, 2001); and for the GLS12 we have used GIA corrections from ICE 5G (Peltier, 2004).

\subsection{Uncertainties in reconstruction due to GIA}

To investigate the sensitivity of GSL to the GIA model we calculate two sea level reconstructions using the same tide gauge dataset (1277 tide gauges) and two GIA correction datasets from the ICE 4G (Peltier, 2001) and the ICE 5G (Peltier, 2004) models http://www.psmsl.org/ train_and_info/geo_signals/gia/peltier/drsl.PSMSL.ICE5G_VM2_L90.txt. The mean difference between GSL is only $3.2 \mathrm{~mm}$, however the maximum difference is $28 \mathrm{~mm}$ during the 1990s. The mean difference in rate is $0.03 \mathrm{~mm} \cdot \mathrm{yr}^{-1}$ for whole time period, however, the maximum difference is $0.6 \mathrm{~mm} \cdot \mathrm{yr}^{-1}$ during 6 decades spanning the $1920-80 \mathrm{~s}$. The differences are almost zero for the past decade.

To further explore the importance of selection of GIA corrections we perform several tests. In addition to the GIA corrections from ICE 4G and ICE 5G models, we use GIA corrections from the open source code SELEN (Spada and Stocchi, 2007; Spada et al., 2012), which solves the "Sea level Equation" (Farrell and Clark, 1976). We named these GIA corrections as S-ICE 3G (SELEN ICE 3G), S-ICE 1 (SELEN ICE 1) and S-KL05 (SELEN Kurt Lambeck 2005). The ice sheet time histories for models SICE 1, S-ICE-3G, and S-ICE-5G were obtained from the works of Peltier and Andrews (1976), Tushingham and Peltier (1991), and Peltier (2004), respectively. We also employ a version of the ice model progressively developed at the Research School of Earth Sciences of the National Australian University by Kurt Lambeck and co-workers (Fleming and Lambeck, 2004), referred to as S-KL05. In all SELEN computations, the mantle is assumed to be incompressible, the rotational feedback on sea-level is taken into account following the theory of Milne and Mitrovica (1998), the fixed-shorelines approximation is used, isostatic equilibrium is assumed before the Last Glacial Maximum, and the geodetic variations are expressed in the reference frame of the centre of mass of the whole Earth. For models S-ICE-3G, S-ICE-5G and S-KL05, the rheological parameters (mantle viscosity profile) are those listed in Table 3 of Spada and Galassi (2012), where the Equivalent Sea Level curves are also given (see their Fig. 10), whereas for S-ICE-1 the same viscosity profile as in S-ICE-3G is employed. It should be remarked that details of our numerical implementation of the "Sea level Equation" and algorithms (Spada et al., 2012) may differ from those in the original works where these ice models have been presented. Thus, rates of GIAinduced sea level change at tide gauges presented here may differ from those obtained by other GIA modellers, even if the same ice sheet chronology is employed. A discussion of the causes of possible differences in GIA models independently developed by various authors is given by Guo et al. (2012).

Additionally we construct a variation of ICE 5G called NEUR5G where we have replaced Northern European GIA corrections with outputs from regionally optimized models for Fennoscandia (Hill et al., 2010), and the British Isles (Bradley et al., 2011).

\subsubsection{Test for the GIA corrections in individual location of tide gauges}

Fig. 9 shows the locations of tide gauge stations and the difference between the GIA corrections from ICE 4G, S-ICE 3G, S-ICE 1 and SKL05 subtracted from the ICE 5G. The largest differences are in Arctic (up to $\pm 8 \mathrm{~mm} \cdot \mathrm{yr}^{-1}$ ), Antarctic and Baltic regions-as may be expected given the evolution of the paleo ice sheets. Douglas (1997) used 24 tide gauges "not from areas deeply covered by ice during the last glacial maximum", with the aim of producing a robust estimate for 20th 

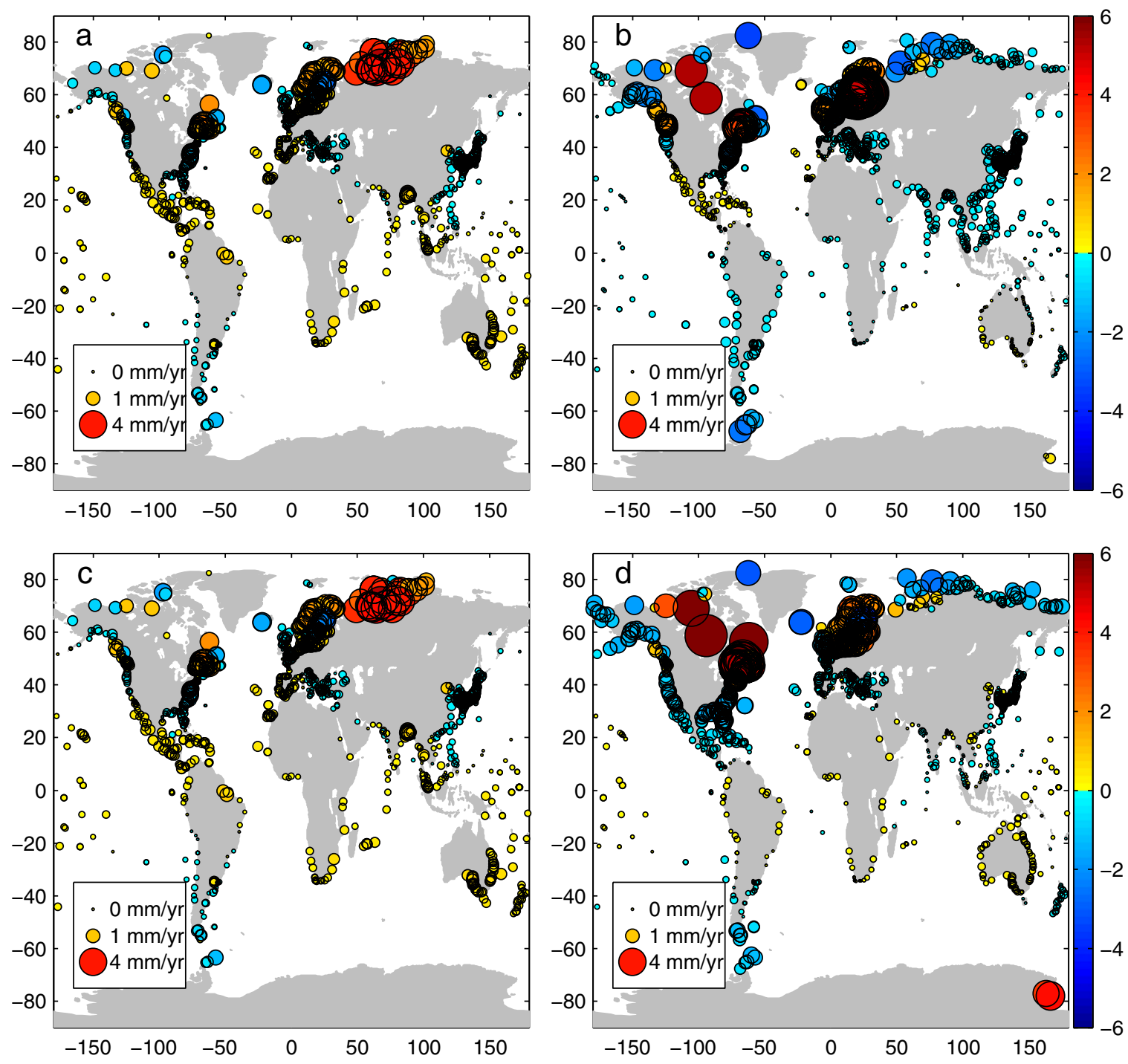

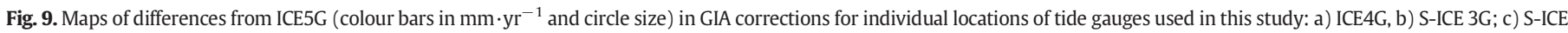
1G; d) S-KL05

century GSL. However, the different GIA corrections make up to $1 \mathrm{~mm} \cdot \mathrm{yr}^{-1}$ differences in rates even for these classic time series. For example, GIA correction for Santa Monica will be changed from $-0.7 \mathrm{~mm} \cdot \mathrm{yr}^{-1}$ (ICE 3G) to $0 \mathrm{~mm} \cdot \mathrm{yr}^{-1}$ (ICE 5G), leading to a 20th century regional trend of $1.4 \mathrm{~mm} \cdot \mathrm{yr}^{-1}$ instead of the $2.1 \mathrm{~mm} \cdot \mathrm{yr}^{-1}$ reported in Douglas (1997). Similarly large discrepancies are found for San Diego, La Jolla, San Francisco and several other tide gauge records often considered to be in far filed from GIA effects (Douglas, 1997).

\subsubsection{GIA tests for global sea level reconstructions}

The aim of our next tests is to quantify the difference in GSLs due to choice of GIA corrections from ICE 5G, ICE 4G, S-ICE 3G, S-ICE 1, S-KL05 and NEUR5G datasets.

3.2.2.1. Idealised case 1 . In this experiment we assume that all tide gauge records are from the same locations as in our study (1277 locations, Fig. 1), however, all these records start at the same time in 1807 and each monthly mean sea level rate is 0 (no sea level rise, no variability and no gaps in tide gauge data), which means that when we assemble our GSL with "virtual station method" we expect the reconstructed sea level rise to be due to GIA corrections only. Fig. 10a shows sea level rise with a constant rate of $0.49 \mathrm{~mm} \cdot \mathrm{yr}^{-1}$ due to the GIA corrections from ICE 5G. We repeat this test for each set of GIA corrections (ICE 4G, S-ICE 3G, S-ICE 1, S-KL05 and NEUR5G) and the results are quite similar, with rates due to GIA corrections varying between 0.3 and $0.6 \mathrm{~mm} \cdot \mathrm{yr}^{-1}$.

3.2.2.2. Idealised case 2 . For each experiment we assume that all tide gauge records are from the same locations as in our study (1277 locations) and all available monthly rates from these locations are replaced with 0 (that is the length of time series and gaps in data are the same as in the original PSMSL database, however, no sea level rise occurs at any location). Again, calculated GSL is only due to GIA corrections (Fig. 10b). In contrast with case 1, the rate of sea level rise varies over time. Fig. 11 shows the spread of idealised case 2 for each of the GIA models in turn, along with their mean. Fig. 11 suggests that estimated global sea level rise during the 20th century could be as much as $3 \mathrm{~cm}$ different depending the GIA corrections used. The different GIA models are not a random sampling of the uncertainty in this adjustment and it is thus not possible to quantify the GIA uncertainty directly. Nevertheless we gauge the GSL uncertainty from GIA to be roughly $0.3 \mathrm{~mm} \cdot \mathrm{yr}^{-1}$ from the spread in Fig. 11. This uncertainty is not explicitly considered in Section 2, but is partially accounted for as the noise parameterisation used in the 

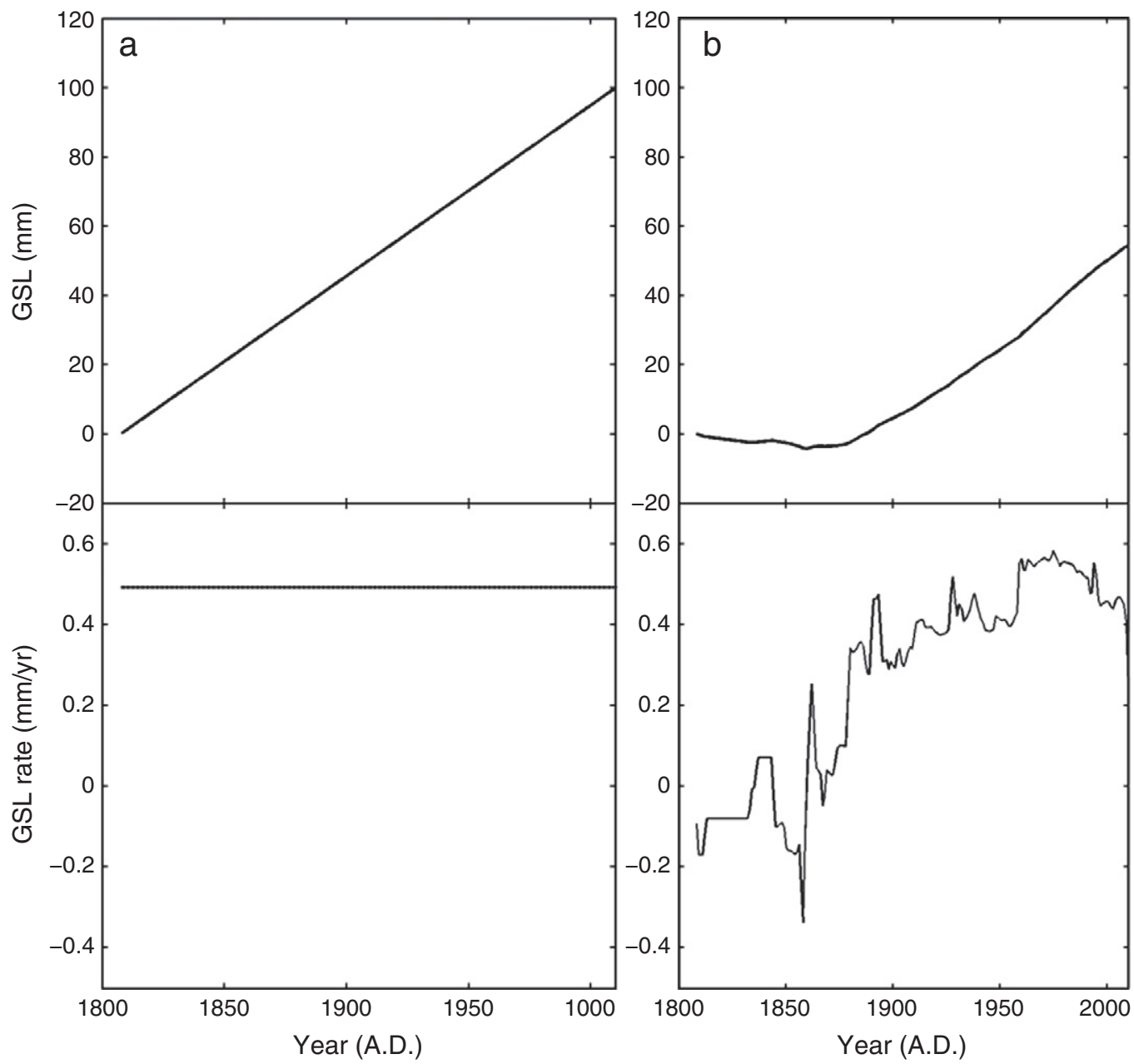

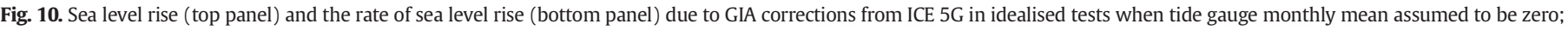

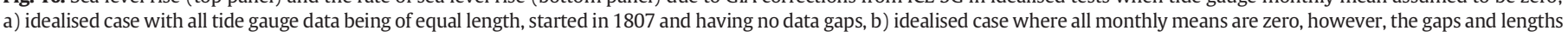
of time series are the same as in original PSMSL datasets.

uncertainty covariance matrix estimation is based on the deviation of the regional to the global mean curves. We observe a large difference between ICE 5G and the modified NEUR5G, considering the small region of the globe where we apply regionally optimized GIA corrections. However, Northern Europe has some of the longest tide gauge records and the GIA will therefore be particularly important in this region.

The shape of sea level rise due to GIA corrections (Fig. 11) could create a bias in the estimate of acceleration in the global sea level. However the acceleration due to GIA corrections alone is an order of magnitude smaller than the acceleration calculated from the GSL reconstruction (Fig. 11).

3.2.3. GIA corrections and regional sea levels (Arctic, Baltic and Antarctic regions)

Selection of the GIA corrections is critical when using Arctic tide gauge records (Fig. 12). Use of two different GIA datasets (ICE 4G and ICE 5G) results in $17 \mathrm{~cm}$ difference for sea level rise since 1925 for the Arctic region, and associated sea level rise rates of $4.7 \mathrm{~mm} \cdot \mathrm{yr}^{-1}$ (ICE 4G) and $2.8 \mathrm{~mm} \cdot \mathrm{yr}^{-1}$ with ICE 5G GIA corrections.

For the Baltic region (not included in our global sea level reconstruction) we test the uncertainties due to GIA corrections with datasets from ICE 5G and Fennoscandian GIA corrections (part of our NEUR5G dataset) estimated by Hill et al. (2010). For Fennoscandian GIA corrections (available for the area of $55-70{ }^{\circ} \mathrm{N}$ and $0-40{ }^{\circ} \mathrm{E}$ ) the Global Positioning System (GPS), tide gauge and Gravity Recovery and Climate experiment (GRACE) data were assimilated into a GIA model. Fig. 13 shows the 20th century trend of $0.3 \mathrm{~mm} \cdot \mathrm{yr}^{-1}$ for ICE $5 \mathrm{G}$ and trend of $2.0 \mathrm{~mm} \cdot \mathrm{yr}^{-1}$ for the Fennoscandian GIA corrections, with $17 \mathrm{~cm}$ difference in sea level rise in Baltic Sea during 1900-2000.

As a test for the Antarctic basin we have used alternative GIA corrections from Thomas et al. (2011), which are available for only four tide gauge locations: Rothera, Scott Base, Cape Roberts and Argentine Islands. The two reconstructions cover the period 1958-2009, with differences in the rate up to $2 \mathrm{~mm} \cdot \mathrm{yr}^{-1}$. For Rothera and Argentine Islands GIA corrections from Thomas et al. (2011) are significantly larger than those from the ICE 5G model, however, these large GIA corrections are associated with break-up of Larsen B Ice shelf and have been applied only for the post breakup period since 2002, and which account for only 2-3 cm of total sea level rise by 2009 .

Our tests show that GIA corrections are large source of uncertainties in tide gauge reconstructions. These tests provide evidence that choice of GIA corrections is very important for at least some regional and hence global reconstructions, with up to $8 \mathrm{~mm} \cdot \mathrm{yr}^{-1}$ for individual tide gauge records, and up to $2 \mathrm{~mm} \cdot \mathrm{yr}^{-1}$ for regional curves leading to up to $0.3 \mathrm{~mm} \cdot \mathrm{yr}^{-1}$ uncertainties in global sea level reconstruction for the period 1900-1999.

\subsection{Regional sea level trends}

When smoothed by a decadal window (Fig. 14), regional sea levels show substantial variability and divergent regional patterns; for example, a strong rise since the 1990s in the central Pacific (cpacific) and at 


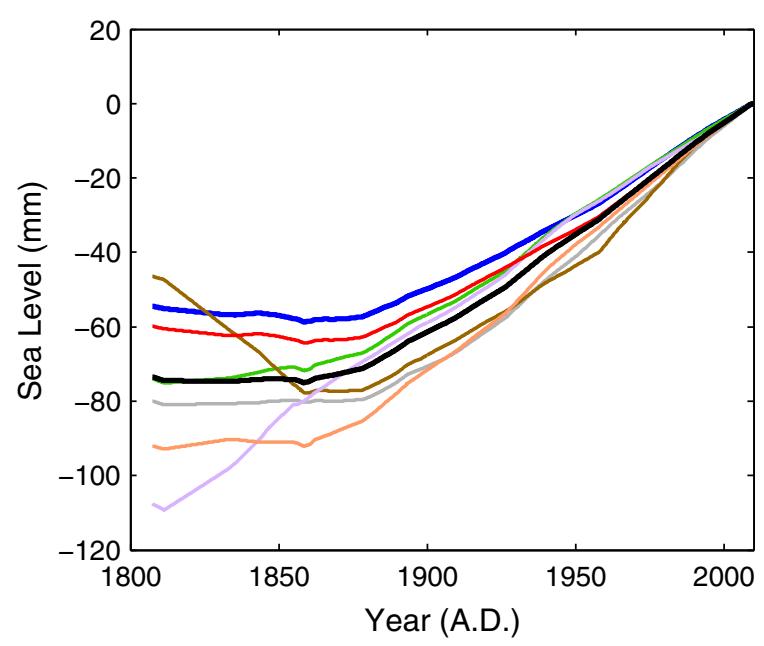

Fig. 11. Sea level rise due to GIA corrections calculated for idealised cases when all monthly means replaced by zero in original tide gauge records; GIA corrections are from: ICE 5G (thick blue, used in present study for GSL12), ICE 4G (grey, used in GSL06), S-ICE 5G (green), S-ICE 3G (brown), S-ICE 1G (red), S-KL05 (violet), NEUR5G (orange) and the mean (thick black). Sea level curves are adjusted assuming zero level in 2010.

the same time a significant fall in north-east Pacific (nepacific). Jevrejeva et al. (2006) discussed the low frequency variability in more detail. Linear trends for the 20th century are presented in Table 1. Only 7 of the 14 regions possess data prior to 1900. The largest rate of sea level rise occurs in the North West Atlantic, with North East Atlantic displaying the smallest linear trend. Over period common to all regions since 1970, the fastest sea level rise has occurred in the polar regions with the ocean close to Antarctica rising at $4.1 \pm 0.8 \mathrm{~mm} \cdot \mathrm{yr}^{-1}$ and the Arctic basin region at $3.6 \pm 0.3 \mathrm{~mm} \cdot \mathrm{yr}^{-1}$ (Table 1 ). For the period $1950-2008$ the rate of sea level rise in Arctic is $2.6 \pm 0.4 \mathrm{~mm} \cdot \mathrm{yr}^{-1}$ which is much faster than the estimate of $1.6 \pm 0.1 \mathrm{~mm} \cdot \mathrm{yr}^{-1}$ by Henry et al. (2012). The difference in the rate can be explained by the
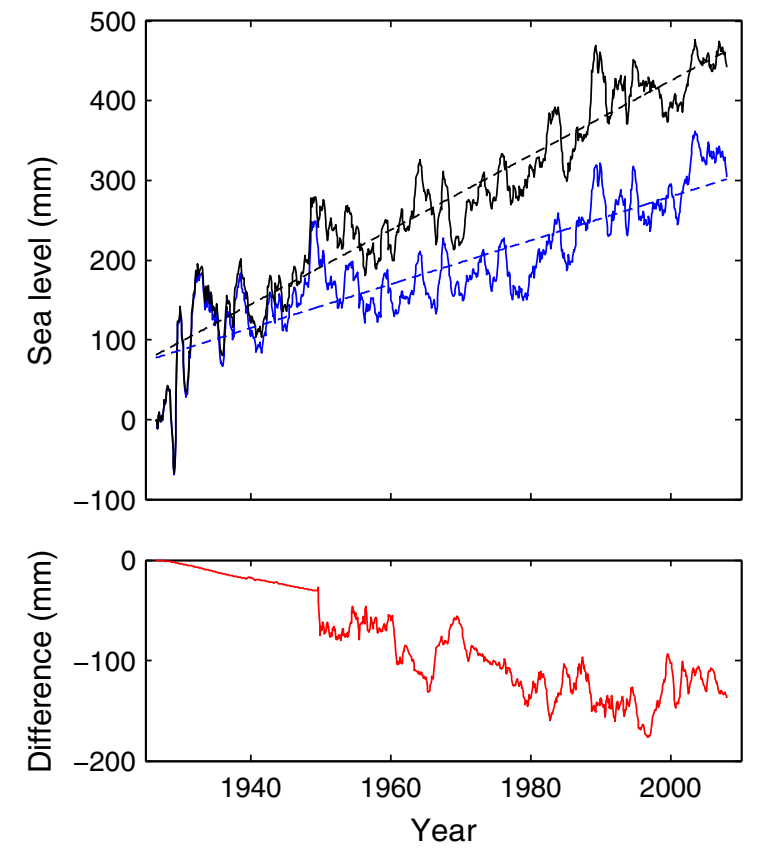

Fig. 12. Arctic sea level with ICE 4G corrections (black) and ICE 5G corrections (blue), with linear trends of $4.7 \mathrm{~mm} \cdot \mathrm{yr}^{-1}$ and $2.8 \mathrm{~mm} \cdot \mathrm{yr}^{-1}$ respectively. Bottom panel is the difference between reconstructions.

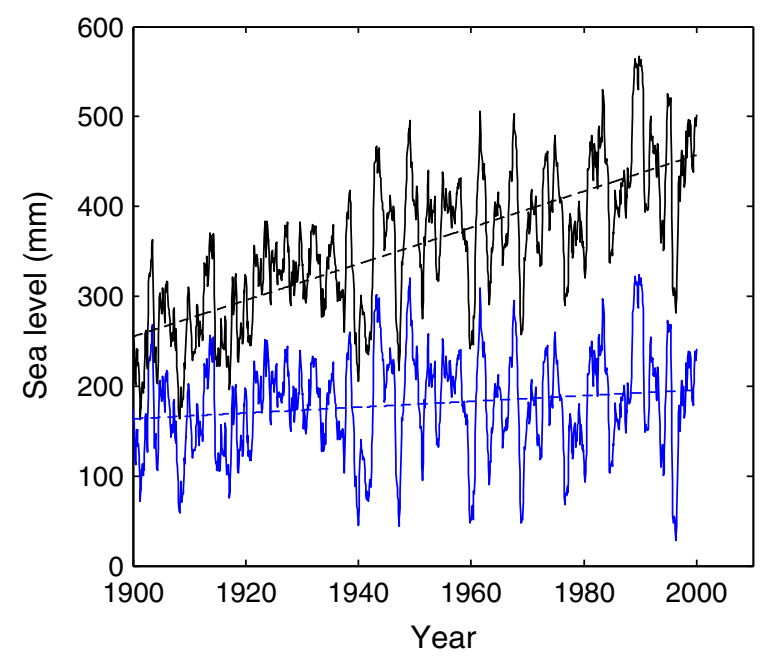

Fig. 13. Sea level reconstruction for Baltic basin with GIA corrections from ICE 5G model (blue) and with Fennoscandian GIA corrections from NEUR5G (black), trends are $0.3 \mathrm{~mm} \cdot \mathrm{yr}^{-1}$ and $2.0 \mathrm{~mm} \cdot \mathrm{yr}^{-1}$.

use of different datasets: 63 tide gauge records from Norway and the Russian Arctic were used by Henry et al. (2012), while we added a further 30 tide gauge records from Canada and Alaska in our study giving essentially circumpolar coverage. Henry et al. (2012) also used an inverse barometer correction, while we do not. The lowest linear trend rates of -0.1 and $-0.7 \mathrm{~mm} \cdot \mathrm{yr}^{-1}$ are observed in Indian and North East Pacific basins, however, the error in trend estimate for the Indian region is $1.3 \mathrm{~mm} \cdot \mathrm{yr}^{-1}$. The global sea level rise rate for the period $1970-2008$ is $1.8 \pm 0.5 \mathrm{~mm} \cdot \mathrm{yr}^{-1}$, which is very similar to the 20th century estimate of $1.9 \pm 0.3 \mathrm{~mm} \cdot \mathrm{yr}^{-1}$. In contrast, there is no consistency between individual regional trends for the period since 1970 and regional trends over the whole 20th century (Table 1).

\subsection{Acceleration in global and regional sea levels}

We estimate an acceleration of $0.02 \pm 0.01 \mathrm{~mm} \cdot \mathrm{yr}^{-2}$ in global sea level by the conventional method, defining the acceleration as the second derivative of sea level with time (twice the quadratic coefficient), measured in $\mathrm{mm} \cdot \mathrm{yr}^{-2}$. We test statistical significance of detected acceleration against a 30 order autoregressive noise model fitted to the difference between the regional sea level curves and global sea level reconstruction. The order is chosen to be sufficiently high to agree reasonably with a Welch periodogram. Using 10,000 Monte Carlo simulations we estimate a 5-95\% confidence interval of $0.01-$ $0.04 \mathrm{~mm} \cdot \mathrm{yr}^{-2}$ for the $0.02 \mathrm{~mm} \cdot \mathrm{yr}^{-2}$ acceleration.

Furthermore, we calculate time variable acceleration using variable windows (from 10 to 190 years), starting from 1807 and sliding the windows year-by-year along the observation period, in order to see the evolution of acceleration depending on the data span and size of the window. Fig. 15 reveals that during the past 203 years there are several time periods with positive and negative sea level accelerations, suggesting that a wide spectrum (from 10 to 100 years) of variability influences estimates of sea level acceleration, and this leads to uncertainty in the quadratic fitting of the GSL depending on the time period selected. Fitting a second order polynomial to the GSL12 for the period 1880-2009 gives an acceleration of $0.001 \mathrm{~mm} \cdot \mathrm{yr}^{-2}$, which is much smaller than the $0.009 \mathrm{~mm} \cdot \mathrm{yr}^{-2}$ reported by Church and White (2011) for that time period. Fig. 15 shows that, at periods longer than 100 years, global sea level reconstruction is characterised by a positive acceleration of $0.02 \mathrm{~mm} \cdot \mathrm{yr}^{-2}$ over the full period of 1807-2009. In a recent study Olivieri and Spada (2013) calculated sea level acceleration of $0.01 \mathrm{~mm} \cdot \mathrm{yr}^{-2}$ since 1820 , which is in good agreement considering the uncertainties of $0.01 \mathrm{~mm} \cdot \mathrm{yr}^{-2}$ in our estimate. 


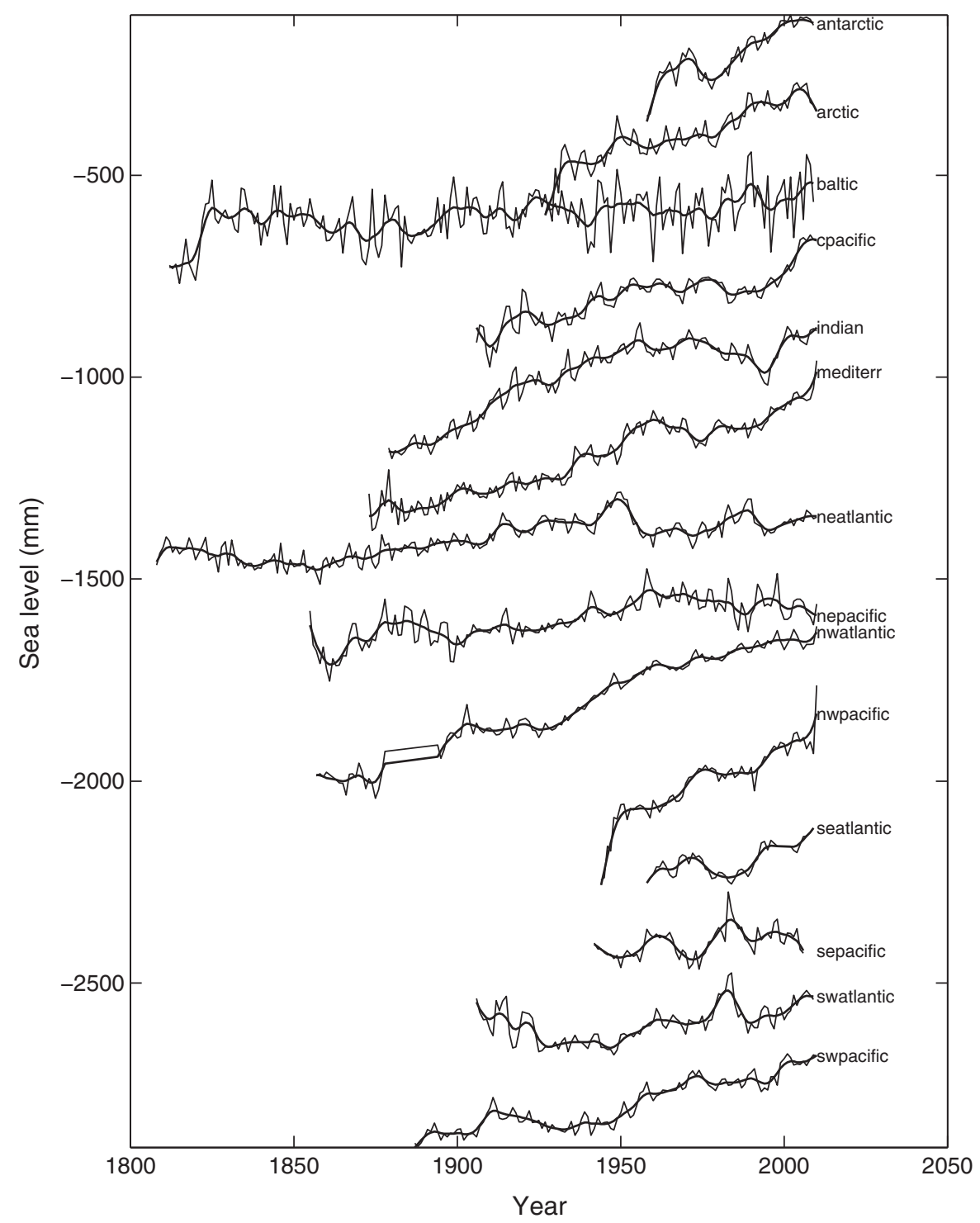

Fig. 14. Regional sea levels with decadal trends (black thick line). Regions are defined in Fig. 1.

Regional sea levels produce a wide range of accelerations (Fig. 15, panels b, c, d), which are to be expected, considering the differences in variability and length of tide gauge records available in our 14 basins. With information available for almost 100 years, some of the regions provide evidence of acceleration (north-east Pacific, south-west Atlantic, south-west Pacific, Arctic), some show deceleration (Indian) or suggest that even 100 years are not enough to make a conclusion about acceleration as variability is very high (north-west Atlantic, as an example). Some signals, however, are shared between regions such as the acceleration in the period from 1920-1960 (Fig. 15), suggesting the coherence in the regional and global sea level rise during 1920-60s. Fast sea level rise in our GSL12 during the 1920-60s is observed while the GSL12 deviates from the CW11 reconstruction (Fig. 8).

The contribution from two components of sea level-melting of glaciers, and thermal expansion of the ocean, provide evidence of acceleration of $0.006 \mathrm{~mm} \cdot \mathrm{yr}^{-2}$ and $0.003 \mathrm{~mm} \cdot \mathrm{yr}^{-2}$ respectively (Fig. 16) since 1800 . The melting component is represented by a reconstruction of glacier volume balance by Leclercq et al. (2011) and steric sea level comes from an ensemble of AOGCM simulations by Gregory et al. (2006). Steric sea level demonstrates strong responses to volcanic eruptions, suggesting a link to natural variability on decadal scales (Hansen et al., 2002; Stenchikov et al., 2009; Moore et al., 2010, 2011). At the same time steric sea level rise during the 20th century is determined mainly by increased anthropogenic forcing (Gregory et al., 2006). Greenland mass loss since 1840 shows an acceleration of $0.002 \mathrm{~mm} \cdot \mathrm{yr}^{-2}$ (Box and Colgan, 2013). We cannot fully account for the $0.02 \mathrm{~mm} \cdot \mathrm{yr}^{-2}$ acceleration in the GSL12 reconstruction with these contributions alone. Accelerating mass loss from Antarctic and Greenland ice sheets since 1992 [Rignot et al., 2011] is an additional source of the recent sea level acceleration.

\section{Discussion}

The time variable estimates of acceleration in 203 years of global sea level reconstruction suggest that there are periods of slow and fast sea level rise associated with decadal variability, which has been previously reported by several authors (Douglas, 1992; Church and White, 2006; Jevrejeva et al., 2008a, 2008b; Woodworth et al., 2009). Several studies (Church and White, 2006, 2011; Jevrejeva et al., 2008a; Woodworth et al., 2009; Olivieri and Spada, 2013) have found various different accelerations in global sea level reconstructions, suggesting that results are very dependent on the time period considered for analysis. In addition, results from individual tide gauges (Douglas, 1992; Watson, 2011; Woodworth et al., 2009) are very dependent on the location and influence of high-frequency (2-15 years) variability. However, Fig. 15 and the associated uncertainties discussed in Section 3.4 show that long 
Table 1

Linear trends for 14 regions (Fig. 1) for the 20th century and since 1970.

\begin{tabular}{|c|c|c|c|c|c|c|}
\hline \multirow[t]{2}{*}{ Basin } & \multicolumn{3}{|l|}{ 1900-1999 } & \multicolumn{3}{|l|}{$1970-2008$} \\
\hline & $\begin{array}{l}\text { Trend } \\
\left(\mathrm{mm} \cdot \mathrm{yr}^{-1}\right)\end{array}$ & Error & 5-95\% conf. interval & $\begin{array}{l}\text { Trend } \\
\left(\mathrm{mm} \cdot \mathrm{yr}^{-1}\right)\end{array}$ & Error & $5-95 \%$ conf. interval \\
\hline Antarctic & $\mathrm{N} / \mathrm{A}$ & $\mathrm{N} / \mathrm{A}$ & $\mathrm{N} / \mathrm{A}$ & 4.1 & \pm 0.8 & $2.9-5.2$ \\
\hline Arctic & $\mathrm{N} / \mathrm{A}$ & $\mathrm{N} / \mathrm{A}$ & $\mathrm{N} / \mathrm{A}$ & 3.6 & $\pm 0.3^{\mathrm{a}}$ & $3.1-4.2$ \\
\hline Baltic $^{\mathrm{b}}$ & 0.3 & $\pm 0.2^{\mathrm{a}}$ & $0.0-0.5$ & 1.7 & $\pm 0.6^{\mathrm{a}}$ & $0.8-2.6$ \\
\hline Cpacific & $\mathrm{N} / \mathrm{A}$ & $\mathrm{N} / \mathrm{A}$ & $\mathrm{N} / \mathrm{A}$ & 2.2 & \pm 1.4 & $0.2-4.2$ \\
\hline Indian & 1.7 & \pm 0.7 & $-0.7-2.7$ & -0.1 & \pm 1.3 & $-2.3-1.7$ \\
\hline Mediterr & 2.2 & \pm 0.3 & $1.7-2.7$ & 2.7 & \pm 0.5 & $2.0-3.5$ \\
\hline Neatlantic & 0.3 & \pm 0.3 & $-0.1-0.7$ & 0.9 & \pm 0.6 & $-0.1-1.9$ \\
\hline Nepacific & 1.1 & \pm 0.3 & $0.6-1.5$ & -0.7 & \pm 0.3 & -1.2 to -0.22 \\
\hline Nwatlantic & 2.7 & \pm 0.2 & $2.4-3.1$ & 1.6 & \pm 0.3 & $1.2-1.9$ \\
\hline Nwpacific & $\mathrm{N} / \mathrm{A}$ & $\mathrm{N} / \mathrm{A}$ & $\mathrm{N} / \mathrm{A}$ & 2.7 & \pm 0.6 & $1.7-3.6$ \\
\hline Seatlantic & $\mathrm{N} / \mathrm{A}$ & $\mathrm{N} / \mathrm{A}$ & $\mathrm{N} / \mathrm{A}$ & $\mathrm{N} / \mathrm{A}$ & $\mathrm{N} / \mathrm{A}$ & $\mathrm{N} / \mathrm{A}$ \\
\hline Sepacific & $\mathrm{N} / \mathrm{A}$ & $\mathrm{N} / \mathrm{A}$ & $\mathrm{N} / \mathrm{A}$ & $\mathrm{N} / \mathrm{A}$ & $\mathrm{N} / \mathrm{A}$ & $\mathrm{N} / \mathrm{A}$ \\
\hline Swatlantic & $\mathrm{N} / \mathrm{A}$ & $\mathrm{N} / \mathrm{A}$ & $\mathrm{N} / \mathrm{A}$ & 1.0 & \pm 0.8 & $-0.3-2.3$ \\
\hline Swpacific & 1.5 & \pm 0.4 & $1.0-2.0$ & 1.3 & \pm 0.6 & $0.5-2.2$ \\
\hline Global & 1.9 & \pm 0.3 & $1.6-2.2$ & 1.8 & \pm 0.5 & $1.3-2.3$ \\
\hline
\end{tabular}

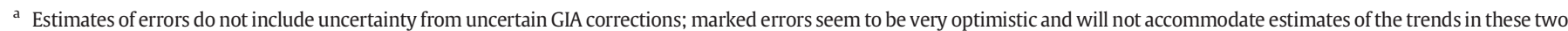
regions with GIA corrections from ICE 4G (Arctic) and from NEUR5G (Baltic).

$\mathrm{b}$ Baltic region has not been included in the global sea level reconstruction.

term estimates of time variable sea level acceleration in 203 year global reconstruction are significantly positive, which supports our previous finding (Jevrejeva et al., 2008a), that despite strong low frequency variability (larger than 60 years) the rate of sea level rise is increasing with time.

Lack of widespread long-term tide gauge records outside Europe prior to the 20th century limits our understanding of trends and acceleration in regional and global sea levels. However, the key components of sea level: melting of glaciers and thermal expansion of the ocean provide evidence of acceleration since 1800. Furthermore the loss of ice mass from Antarctica and Greenland ice sheets has been increasing over the past decades (Chen et al., 2006; Rignot et al., 2011; Velicogna, 2009; Box and Colgan, 2013), suggestive of a link to global climate change. It is debatable whether acceleration of sea level rise in the 20th century is due to anthropogenic climate change. Sea level simulated by Jevrejeva et al. (2009) shows that the difference in volcanic cooling amounts of $7 \mathrm{~cm}$ of sea level rise in the 20th century, superimposed on the global ocean warming (Levitus et al., 2012). Increased melting of ice sheets and glaciers is attributable to increasing temperatures (Box, 2013; Leclercq and Oerlemans, 2012).
The highly clustered geographical distribution of tide gauges along the continental margins and some ocean islands means that the GIA corrections do not cancel out in the final global sea level estimate. The estimated trend in global sea level rise due to this GIA correction is in the order of $0.3-0.6 \mathrm{~mm} \cdot \mathrm{yr}^{-1}$ in our idealised "test 1 ". We would expect the rate of sea level rise due to GIA correction to be equal to zero in our idealised case 1 if we had homogeneous global sampling of sea level in equally distributed grid points covering coastal and ocean areas in both hemispheres. Idealised case 2 shows that the temporal inhomogeneity of data availability also creates apparent trends in sea level, and accelerations, though these appear to be much smaller than acceleration in GSL reconstructions, and hence cannot contribute to attribution studies of GSL acceleration.

\section{Conclusion}

Global sea level reconstruction based on 1277 tide gauges records has been used to determine global and regional sea level changes from 1807 to 2010. There is an excellent agreement between the linear trends from GSL12 and satellite altimetry sea level since 1993, with rates of

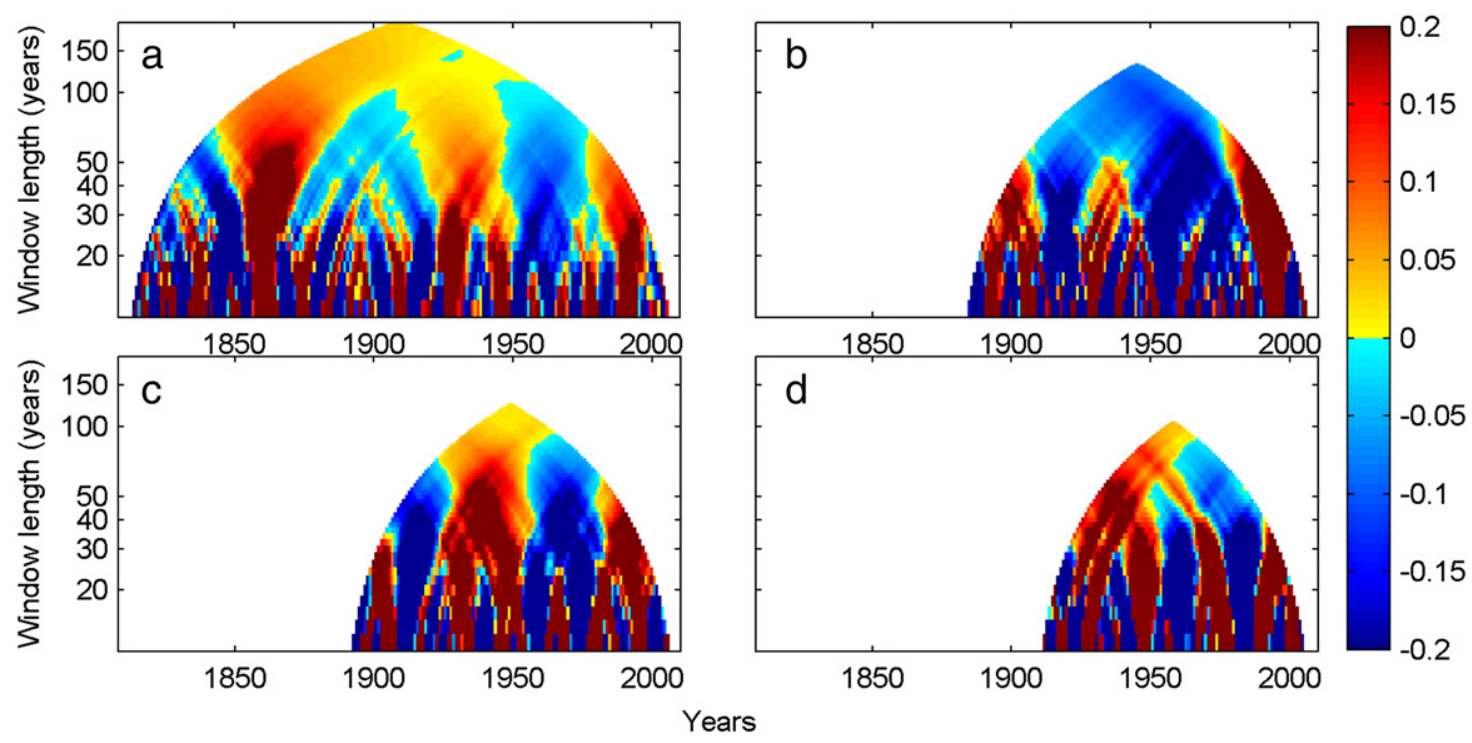

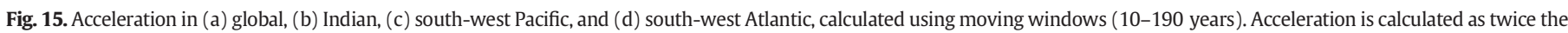
quadratic coefficient of the second order polynomial fit (colour bar in $\mathrm{mm} \cdot \mathrm{yr}^{-2}$ ). Uncertainty of the whole period acceleration is estimated at $0.01 \mathrm{~mm} \cdot \mathrm{yr}^{-2}$ (see Section 3.4 ). 

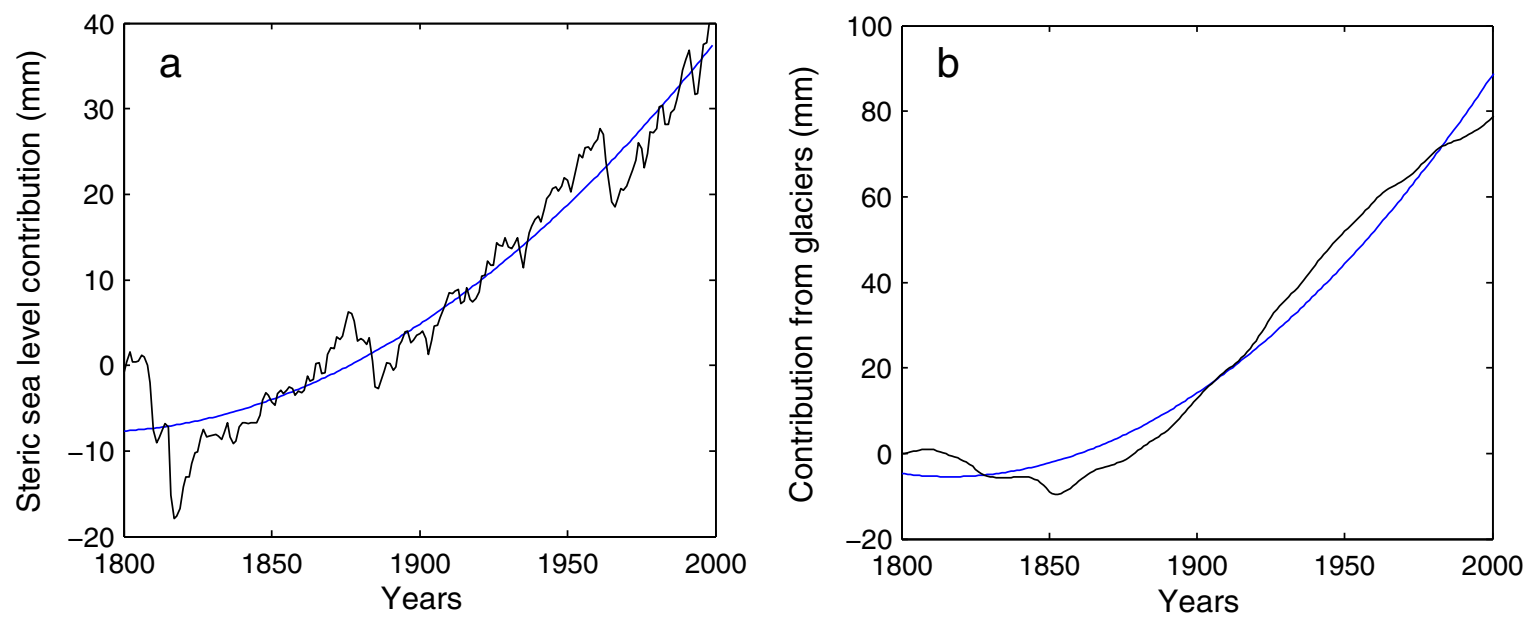

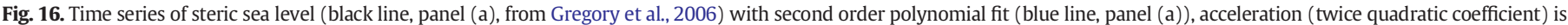

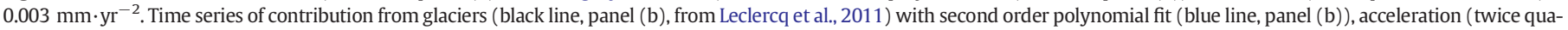
dratic coefficient) is $0.006 \mathrm{~mm} \cdot \mathrm{yr}^{-2}$.

$3.1 \pm 0.6 \mathrm{~mm} \cdot \mathrm{yr}^{-1}$ and of $3.2 \pm 0.4 \mathrm{~mm} \cdot \mathrm{yr}^{-1}$ respectively. GSL12 shows a linear trend of $1.9 \pm 0.3 \mathrm{~mm} \cdot \mathrm{yr}^{-1}$ during the 20th century and $1.8 \pm 0.5 \mathrm{~mm} \cdot \mathrm{yr}^{-1}$ for the period $1970-2008$. Regional decadal trends demonstrate diversity since 1970 with the fastest regional linear trends of $4.1 \mathrm{~mm} \cdot \mathrm{yr}^{-1}$ in the Antarctic region and $3.6 \mathrm{~mm} \cdot \mathrm{yr}^{-1}$ for the Arctic basin. Our 203-year long reconstruction provides evidence of positive acceleration for periods longer than 100 years, however, values of acceleration in regional curves fluctuate considerably due to strong decadal and multi-decadal oscillations in regional sea level records. The steric and mass sea level components, according to the limited data and simulations available extending back to 1800 , demonstrate an acceleration of $0.006 \mathrm{~mm} \cdot \mathrm{yr}^{-2}$ and $0.003 \mathrm{~mm} \cdot \mathrm{yr}^{-2}$ respectively.

The large uncertainties (up to $0.3-0.6 \mathrm{~mm} \cdot \mathrm{yr}^{-1}$ ) in our global sea level reconstruction are due to choice of GIA corrections, with difference up to $8 \mathrm{~mm} \cdot \mathrm{yr}^{-1}$ in rate of sea level rise in individual locations, such as the Arctic, Baltic and Antarctic regions. The GIA correction adds up to $0.3 \mathrm{~mm} \cdot \mathrm{yr}^{-1}$ trend in the global sea level reconstruction, with large differences between GIA datasets. This uncertainty can also be substantial at sites that are traditionally considered far-field (e.g. Douglas, 1997). This suggests a need for further constraining GIA models, especially in the Arctic and Antarctic where rapid mass change is occurring if we would like to use tide gauge records from these important regions with more confidence.

\section{Acknowledgement}

This work was supported by China's National Key Science Program for Global Change Research (Nos: 2010CB950504, 2010CB951401 and 2012CB957704), and NERC consortium "Using Inter-glacial to assess future sea level scenarios" (NE/I008365/1), and NSFC No. 41076125, and is publication number 10 of the Nordic Centre of Excellence SVALI, Stability and Variations of Arctic Land Ice funded by the Nordic Top-level Research Initiative. The programme SELEN (v. 2.9) is available from the Computational Infrastructure for Geodynamics at the page http:// www.geodynamics.org/cig/software/selen. Giorgio Spada is supported by a grant from Dipartimento di Scienze di Base e Fondamenti of the Urbino University. K. Lambeck is acknowledged for kindly providing the ice sheet chronology of the KL05 model. D. Peltier is acknowledged for kindly providing outputs from the ICE $5 \mathrm{G}$ model to the PSMSL. We would like to thank Anny Cazenave and anonymous reviewer for helpful comments that improved our manuscript.

\section{References}

Becker, M., Meyssignac, B., Letetrel, C., Llovel, W., Cazenave, A., Delcroix, T., 2012. Sea level variations at tropical Pacific islands since 1950. Global Planet Change 80-81, 85-98. http://dx.doi.org/10.1016/j.gloplacha.2011.09.004.

Bindoff, N.L., Willebrand, J., Artale, V., Cazenave, A., Gregory, J., Gulev, S., Hanawa, K., Le Quere, C. Levitus, S., Nojiri, Y., Shum, C.K., Talley, L.D., Unnikrishnan, A., 2007. Observations: oceanic climate change and sea level. In: Solomon, S., Qin, D., Manning, M., Chen, Z., Marquis, M., Averyt, K.B., Tignor, M., Miller, H.L. (Eds.), Climate change 2007: The physical science basis. Contribution of Working Group I to the Fourth Assessment Report of the Intergovernmental Panel on Climate Change. Cambridge University Press, Cambridge.

Boening, C., Willis, J.K., Landerer, F.W., Nerem, R.S., Fasullo, J., 2012. The 2011 La Niña: So strong, the oceans fell. Geophys. Res. Lett. 39, L19602. http://dx.doi.org/10.1029/ 2012GL053055

Box, J.E., 2013. Greenland ice sheet mass balance reconstruction. Part II: surface mass balance (1840-2010). J. Clim. http://dx.doi.org/10.1175/JCLI-D-12-00518.1.

Box, J.E., Colgan, W., 2013. Greenland ice sheet mass balance reconstruction. Part III: marine ice loss and total mass balance (1840-2010). J. Clim. http://dx.doi.org/10.1175/ JCLI-D-12-00546.1.

Bradley, S., Milne, G., Shennan, I., Edwards, R.J., 2011. An improved glacial isostatic adjustment model for the British Isles. J. Quat. Sci. 26 (5), p541-p552. http://dx.doi.org/ 10.1111/j.1365-246X.2008.04033.X.

Cazenave, A., et al., 2012. Estimating ENSO influence on the global mean sea level, 1993-2010. Mar. Geod. 35, 82-97. http://dx.doi.org/10.1080/01490419.2012.718209.

Chen, J.L., Wilson, C.R., Tapley, B.D., 2006. Satellite gravity measurements confirm accelerated melting of Greenland ice sheet. Science 313, 1958-1960. http://dx.doi.org/ $10.1126 /$ science. 1129007.

Church, J.A., White, N.J., 2006. A 20th century acceleration in global sea-level rise. Geophys. Res. Lett. 33, L01602. http://dx.doi.org/10.1029/2005GL024826.

Church, J.A., White, N.J., 2011. Sea-level rise from the late 19th to the early 21st Century. Surv. Geophys. http://dx.doi.org/10.1007/s10712-011-9119-1.

Davis, J.L., Mitrovica, J.X., 1996. Glacial isostatic adjustment and the anomalous tide gauge record of eastern North America. Nature 379, 331-333.

Douglas, B.C. 1992. Global sea level acceleration. J. Geophys. Res. 97 (C8), 12699-12706.

Douglas, B.C., 1997. Global sea rise: a redetermination. Surv. Geophys. 18, 270-292.

Farrell, W.E., Clark, J.A., 1976. On postglacial sea-level. Geophys. J. R. Astron. Soc. 46, 647-667.

Fleming, K., Lambeck, K., 2004. Constraints on the Greenland ice sheet since the Last Glacial Maximum from sea level observations and glacial-rebound models. Quat. Sci. Rev. 23 (9-10), 1053-1077.

Gornitz, V., Lebedeff, S., Hansen, J., 1982. Global sea level trend in the past century, Science 215 (4540), 1611-1614.

Gregory, J.M., Lowe, J.A., Tett, S.F.B., 2006. Simulated global mean sea level change over the last half-millennium. J. Clim. 19 (18), 4576-4591.

Grinsted, A., Moore, J.C., Jevrejeva, S., 2007. Observational evidence for volcanic impact on sea level and the global water cycle. PNAS 104 (50), 19730-19734. http://dx.doi.org/ 10.1073 pnas.0705825104.

Grinsted, A., Moore, J.C., Jevrejeva, S., 2010. Reconstructing sea level from paleo and projected temperatures 200 to 2100 AD. Clim. Dyn. 34, 461-472.

Guo, J.Y., Huang, Z.H., Shum, C.K., van der Wal, W., 2012. Comparison among contemporary glacial isostatic adjustment models. J. Geodyn. 61, 129-137.

Hansen, J., et al., 2002. Climate forcings in Goddard Institute for Space Studies SI2000 simulations. J. Geophys. Res. 107 (D18), 4347. http://dx.doi.org/10.1029/2001JD001143.

Henry, O., Prandi, P., Llovel, W., Cazenave, A., Jevrejeva, S., Stammer, D., Meyssignac, B., Koldunov, N., 2012. Tide gauge-based sea level variations since 1950 along the 
Norwegian and Russian coasts of the Arctic Ocean: contribution of the steric and mass components, J. Geophys. Res. 117, C06023. http://dx.doi.org/10.1029/ 2011JC007706.

Hill, E.M., Davis, J.L., Tamisiea, M.E., Lidberg, M., 2010. Combination of geodetic observations and models for glacial isostatic adjustment fields in Fennoscandia. J. Geophys. Res. 115, B07403. http://dx.doi.org/10.1029/2009JB006967.

Holgate, S.J., 2007. On the decadal rates of sea level change during the twentieth century. Geophys. Res. Lett. 34, L01602. http://dx.doi.org/10.1029/2006GL028492.

Holgate, et al., 2013. New data systems and products at the permanent service for mean sea level. J. Coast. Res. 29 (3), 493-504.

Jevrejeva, S., Grinsted, A., Moore, J.C., Holgate, S., 2006. Nonlinear trends and multi-year cycle in sea level records. J. Geophys. Res. 111 (2005JC003229).

Jevrejeva, S., Moore, J.C., Grinsted, A., Woodworth, P.L., 2008a. Recent global sea level acceleration started over 200 years ago? Geophys. Res. Lett. 35. http://dx.doi.org/ 10.1029/2008GL033611.

Jevrejeva, S., Moore, J.C., Grinsted, A., 2008b. Relative importance of mass and volume changes to global sea level rise. J. Geophys. Res. 113, D08105. http://dx.doi.org/ 10.1029/2007JD009208.

Jevrejeva, S., Grinsted, A., Moore, J.C., 2009. Anthropogenic forcing dominates sea level rise since 1850. Geophys. Res. Lett. 36. http://dx.doi.org/10.1029/2009GL040216.

King, M.A., Keshin, M., Whitehouse, P.L., Thomas, I.D., Milne, G., Riva, R.E.M., 2012. Regional biases in absolute sea-level estimates from tide gauge data due to residual unmodeled vertical land movement. Geophys. Res. Lett. 39 (14), L14604.

Leclercq, P.W., Oerlemans, L., 2012. Global and hemispheric temperature reconstruction from glacier length fluctuations. Clim. Dyn. 38 (5-6), 1065-1079.

Leclercq, P.W., Oerlemans, J., Cogley, J.G., 2011. Estimating the glacier contribution to sealevel rise over the period 1800-2005. Surv. Geophys. 32, 519-535. http://dx.doi.org/ 10.1007/s10712-011-9121-7.

Levitus, S., et al., 2012. World ocean heat content and thermosteric sea level change (0-2000), 1955-2010. Geophys. Res. Lett. http://dx.doi.org/10.1029/2012GL05110.

Merrifield, M.A., Merrifield, S.T., Mitchum, G.T., 2009. An anomalous recent acceleration of global sea level rise. J. Clim. 22, 5772-5781. http://dx.doi.org/10.1175/ 2009JCLI2985.1.

Milne, G.A., Mitrovica, J.X., 1998. Postglacial sea-level change on a rotating Earth. Geophys. J. Int. 133, 1-10.

Milne, G.A., Davis, J.L., Mitrovica, J.X., Scherneck, H.-G., Johansson, J.M., Vermeer, M., Koivula, H., 2001. Space-geodetic constraints on glacial isostatic adjustment in Fennoscandia. Science 291, 2381-2385.

Moore, J.C., Jevrejeva, S., Grinsted, A., 2010. Efficacy of geoengineering to limit 21st century sea-level rise. PNAS. http://dx.doi.org/10.1073/pnas.1008153107.

Moore, J.C., Jevrejeva, S., Grinsted, A., 2011. The historical sea level budget. Ann. Glaciol. 52 (59).

Moore, J.C., Grinsted, A., Zwinger, T., Jevrejeva, S., 2013. Semiempirical and process-based global sea level projections. Rev. Geophys. 51. http://dx.doi.org/10.1002/rog.20015.

Olivieri, M., Spada, G., 2013. Intermittent sea-level acceleration. Glob. Planet. Chang. 109, 64-72.
Peltier, W.R. 2001. Global glacial isostatic adjustment and modern instrumental records of relative sea level history. In: Douglas, B.C., Kearney, M.S., Leatherman, S.P. (Eds.), Sea Level Rise. Elsevier, New York, pp. 65-93.

Peltier, W.R., 2004. Global glacial isostasy and the surface of the ice-age Earth: the ICE-5G (VM2) model and GRACE. Annu. Rev. Earth Planet. Sci. 32, 111-149.

Peltier, W.R., Andrews, J.T., 1976. Glacial isostatic adjustment, I, the forward problem. Geophys. J. R. Astron. Soc. 46, 605-646.

Prandi, P., Cazenave, A., Becker, M., 2009. Is coastal mean sea level rising faster than the global mean? A comparison between tide gauges and satellite altimetry over 1993-2007. Geophys. Res. Lett. 36, L05602. http://dx.doi.org/10.1029/ 2008 GL036564.

Ray, R.D., Douglas, B.C., 2011. Experiments in reconstructing twentieth-century sea levels. Prog. Oceanogr. 91, 495-515.

Rignot, E., Velicogna, I., van den Broeke, M.R., Monaghan, A., Lenaerts, J., 2011. Acceleration of the contribution of the Greenland and Antarctic ice sheets to sea level rise. Geophys. Res. Lett. 38 (5503), 2011.

Spada, G., Galassi, G., 2012. New estimates of secular sea level rise from tide gauge data and GIA modelling. Geophys. J. Int. 191 (3), 1067-1094.

Spada, G., Stocchi, P., 2007. SELEN: a Fortran 90 program for solving the "Sea Level Equation”. Comput. Geosci. 33 (4), 538-562. http://dx.doi.org/10.1016/j.cageo. 2006.08.006.

Spada, G., Melini, D., Galassi, G., Colleoni, F., 2012. Modeling sea level changes and geodetic variations by glacial isostasy: the improved SELEN code. arXiv preprint:1212.5061.

Stenchikov, G., et al., 2009. Volcanic signals in oceans. J. Geophys. Res. 114, D16104 http://dx.doi.org/10.1029/2008JD011673.

Thomas, I.D., et al., 2011. Widespread low rates of Antarctic glacial isostatic adjustment revealed by GPS observations. Geophys. Res. Lett. 38, L22302. http://dx.doi.org/ 10.1029/2011GL049277.

Tushingham, A.M., Peltier, W.R., 1991. ICE-3G-a new global model of late Pleistocene deglaciation based upon geophysical predictions of Post-Glacial relative sea leve change. J. Geophys. Res. 96, 4497-4523.

Velicogna, I., 2009. Increasing rates of ice mass loss from the Greenland and Antarctic ice sheets revealed by GRACE. Geophys. Res. Lett. 36, L19503. http://dx.doi.org/10.1029/ 2009GL040222.

Watson, P.J., 2011. Is there evidence yet of acceleration in mean sea level rise around mainland Australia? J. Coast. Res. 27 (2), 368-377.

Welch, P.D., 1967. The use of fast Fourier transform for the estimation of power spectra: a method based on time averaging over short, modified periodograms. IEEE Trans. Audio Electroacoust. AU-15, 70-73.

Woodworth, P.L., White, N., Jevrejeva, S., Holgate, S., Church, J.A., Gehrels, W.R., 2009. Evidence for the accelerations of sea level on multi-decade and century timescales. Int. J. Climatol. 29, 777-789. http://dx.doi.org/10.1002/joc.1771.

Woppelmann, G., Letetrel, C., Santamaria, A., Bouin, M.N., Collilieux, X., Altamimi, Z. Williams, S.D.P., Martin Miguez, B., 2009. Rates of sea-level change over the past century in a geocentric reference frame. Geophys. Res. Lett. 36, L12607. http://dx.doi.org/ 10.1029/2009GL038720. 